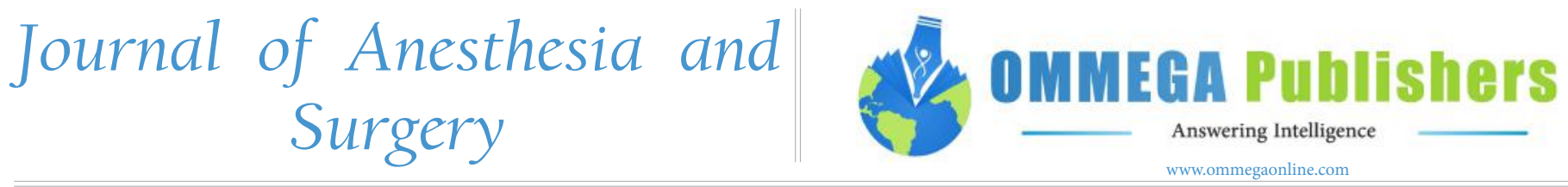

Research Article

\title{
Innovative Methods of Anaesthesia for Eye Surgery in Children
}

\author{
Mehul A. Shah*, Shreya M. Shah, Janak D. Kalyani, Jaimini S. Pandya, Niray L. Patel \\ Drashti Netralaya, Dahod, Gujarat, India
}

Received date: June 26, 2014

Accepted date: March 27, 2015

Published date: March 30, 2015

*Corresponding author: Mehul A. Shah, Drashti Netralaya, Nr. GIDC, Chakalia Road. Dahod-389151 Gujarat Tel: 0091-2673-645364 Fax: 00-91-2673-221232; Email: omtrust@rdiffmail.com

Citation: Mehul, A. Shah., et al. Innovative methods of Anesthesia for eye surgery in children. (2015) J Anesth Surg 2(1): 37-39.

Keywords: Ocular injuries; Regional anaesthesia; Traumatic cataracts; Open globe injury; General anaesthesia

\begin{abstract}
Background: To study effectiveness of innovative method of anaesthesia using regional anaesthesia for eye surgeries in paediatric age group.

Material and Methods: This is a retrospective study done at tertiary eye care center in central western India. We retrieved data from Medical Record Department for all children (0 to 18 ) who had undergone ocular surgeries between January 2008 to December 2013 at tertiary eye care centre.

Sedation along with regional anaesthesia (topical or peribulbar block) or general anaesthesia was the preferred mode of anaesthesia under which cataract, strabismus, lacrimal, ocular trauma and retinal surgeries were performed. All surgeries, methods, medicines and complications of anaesthesia were properly documented.

Results: In all, 1941 cases were operated. Among them 1084 were males and 857 were females; 520 were cataract surgeries, 723 were strabismus surgeries, 285 were lacrimal surgeries, 185 were ocular trauma and 228 were retinal surgeries. All data analysed using SPSS 22 with descriptive methods and cross tabulation. Median age of patients was $8+/-4.8(0$ to 17$)$. All surgeries were eventless and no serious perioperative complication was encountered.

Conclusion: Combination of sedation and regional anaesthesia is a good cost effective method for ocular anaesthesia in children for eye surgeries.

to be appropriate for those traumas extensive enough to require surgical intervention, but the anaesthetist must balance specific risks: force placed upon the eye during anaesthesia manoeuvres such as mask-ventilation, laryngoscopy, and intubation, or due to coughing or bucking. Western experience might not prove useful because of our socio-economic and demographic factors. We have tried to study this innovative method of anaesthesia which is cost effective and does not need very expensive infrastructure, in order to provide evidence that this method can offer solutions for safe and cost effective anaesthesia for children undergoing eye surgeries.
\end{abstract}

\section{Introduction}

Childhood blindness is one of the most important factors causing social and economic burden to society ${ }^{[1-6]}$. It is also one the leading causes of blindness. Since blind children's life span is usually greater than adult blinds, their lives become more painful, abnormal, and dependent. Common causes of blindness in paediatric age group are refractive errors, congenital malformations, Cataract, Strabismus, Ocular injuries etc ${ }^{[6,7,8]}$.

Amongst these many are treatable causes. Now with VISON 2020 and NPCB initiatives childhood blindness elimination is an important branch. Now a days more and more students are choosing paediatric ophthalmology as their sub speciality, availing themselves of many training programs ${ }^{[1,2]}$. As many as 40 centres in our country are working for this cause in tandem with government as well as Non Government Organizations. Some NGOs like ORBIS international have taken up initiative for elimination of childhood blindness.

One of the main obstacles to this specialty is anaesthesia for paediatric eye surgeries. And expertise in this field is not easily and readily available in our country. We need to have different consideration for different ocular condition: as in open globe ocular injuries intra ocular pressure is the issue to take care of; the shadow of oculo cardiac reflex is always lurking in neighbourhood in strabismus surgeries and possibility of aspiration when irrigation is done in lacrimal surgeries can never be ignored $^{[9]}$. General anaesthesia has traditionally been considered

\section{Material and Methods}

Approval obtained from Hospital ethical committee for this study. In this retrospective study we enrolled children 0-18 years our Electronic Medical Records who had undergone any type of eye surgery during January 2004 to December 2013. We documented all details about pre, per and post -operative, data.

We have also documented methods of single or combination anaesthesia methods. They included general anaesthesia using anaesthetic agents, general with regional anaesthesia in the form of topical anaesthesia (Lignocaine 4\%) or peri bulbar block using (Lignocaine 2\% and Sensorcaine 0.5\%). Endo tracheal intubation, Laryngeal mask or I gel were used to maintain air way. In All these cases Intravenous Anaesthesia was administered. The manner of anaesthesia was decided on the basis of

Copy rights: (C2015 Mehul, A. Shah. This is an Open access article distributed under the terms of Creative Commons Attribution 
type of surgery. Significant deciding factors were Intra ocular pressure, oculo cardiac reflex and integrity of ocular walls. All these procedures were done at National Accreditation Board of Hospitals accredited eye hospital having tertiary care facilities. All patients were given Premedication in form Glycopyrolate and Ondansetron.

For all wound repair topical with total Intravenous Anaesthesia along with Laryngeal Mask Airway/IGEL was used. This method was selected in order to facilitate the control of IOP.

For all lacrimal surgery endotracheal intubation with intra venous anaesthesia was employed. Endo tracheal intubation prevented the chance aspiration due to irrigation done during lacrimal surgeries.

For all cataracts including traumatic cataracts total intravenous anaesthesia along with peribulbar was preferred; as peribulbar block helped maintain the IOP during surgeries.

In case of Strabismus surgeries Total intravenous Anaesthesia in conjunction with Peribulbar block was given preference as it minimised the probability of oculo cardiac reflex. For retinal surgeries concern for oculo cardiac reflex and IOP tilted the choice in favour of total intravenous anaesthesia and peri bulbar block.

Post-operative regimen: Post-operative monitoring was done at surgical ICU in presence of a qualified nurse and an anaesthetist. All post-operative anaesthesia complications were documented. All data was exported to excel sheet and analysed with SPSS 22. Descriptive statistics and frequency were used to analyse these data.

\section{Results}

In all 1941 cases including 1084 males and 857 females (Table-1) out of which 520 were cataract, 723 were strabismus, 285 were lacrimal surgeries, 185 were ocular trauma and 228 retinal surgeries- were operated.(Table-2) Median age of patients was $8+/-4.8(0$ to 17$)$. All the surgeries were accomplished uneventful manner. We could administer anaesthesia in $83.3 \%$ cases with general and regional anaesthesia (Table-3, 4, 5). We did not come across any significant anaesthesia complication except in 2 patients who developed bleeding during nasolacrimal intubation, but as endotracheal intubation was on any untoward sequelae was averted Post-operative nausea vomiting (PONV) in $5 \%$ cases was documented.

Tables-1 Age and sex distribution

\begin{tabular}{|c|c|c|c|}
\hline \multirow{2}{*}{} & \multicolumn{2}{|c|}{ sex } & \multirow{2}{*}{ Total } \\
\cline { 2 - 3 } & Female & Male & \\
\hline 0 to 1 & 82 & 94 & 176 \\
\hline 2 to 5 & 182 & 261 & 443 \\
\hline 6 to 10 & 289 & 338 & 627 \\
\hline 11 to 18 & 304 & 391 & 695 \\
\hline Total & 857 & 1084 & 1941 \\
\hline
\end{tabular}

Table-2 Methods of anaesthesia according to type of surgeries
\begin{tabular}{|l|l|l|}
\hline Type of Surgeries & Number (n) & Percent (\%) \\
\hline Lacrimal-Probing & 285 & 14.7 \\
\hline Lens Vitrectomy & 228 & 11.7 \\
\hline pediatric cataract & 520 & 26.8 \\
\hline Squint & 723 & 37.2 \\
\hline Wound Repair & 185 & 9.5 \\
\hline Total & 1941 & 100.0 \\
\hline
\end{tabular}

Table-3 Type of regional anaesthesia

\begin{tabular}{|l|l|l|}
\hline & Number $(\mathrm{n})$ & Percent $(\%)$ \\
\hline NIL & 285 & 14.7 \\
\hline PB & 1471 & 75.8 \\
\hline TOPICAL & 185 & 9.5 \\
\hline Total & 1941 & 100.0 \\
\hline
\end{tabular}

Table-4 Type of Airway maintenance used

\begin{tabular}{|l|l|l|}
\hline & Number (n) & Percent (\%) \\
\hline ETI & 285 & 14.7 \\
\hline IGEL & 6 & .3 \\
\hline LMA & 5 & .3 \\
\hline TIVA & 1645 & 84.8 \\
\hline Total & 1941 & 100.0 \\
\hline
\end{tabular}

Table-5 Distribution of type of anaesthesia

\begin{tabular}{|l|l|l|}
\hline Type of anaesthesia & Number $(\mathrm{n})$ & Percent $(\%)$ \\
\hline ETI+GA & 285 & 14.7 \\
\hline TIVA+PB & 1472 & 75.8 \\
\hline TIVA+TOPICAL & 171 & 8.8 \\
\hline TIVE+TOPICAL & 2 & .1 \\
\hline TOPICAL+IGEL & 6 & .3 \\
\hline TOPICAL+LMA & 5 & .3 \\
\hline Total & 1941 & 100.0 \\
\hline
\end{tabular}

\section{Discussion}

In all 1941 cases including 1084 males and 857 females- (Table-1) out of which 520 were cataract, 723 were strabismus, 285 were lacrimal surgeries, 185 were ocular trauma and 228 retinal were surgeries- were operated.(Table-2) Median age of patients was $8+/-4.8(0$ to 17$)$.

Childhood blindness is an important initiative of vision 2020. We have very limited number of paediatric anaesthetist which is a hindrance to successful outcome of childhood blindness ${ }^{[1,2]}$. Most of the anaesthetists are not familiar with specific technical complexities of paediatric ocular conditions ${ }^{[1,2]}$. General anaesthesia has traditionally been considered to be appropriate for anaesthesia in children ${ }^{[10,11]}$. But now techniques for anaesthesia in children for ocular surgeries are re strategized keeping in view specific issues regarding the type of surgeries, cost effectiveness and expertise of anaesthetist ${ }^{[12]}$.

Auffarth et al reported topical anaesthesia for open globe injury ${ }^{[13]}$ but number of cases are very small as compared to current study. Frenesco has reported sedation along with topical lignocaine for open globe injury ${ }^{[14]}$. Steven gayer has reported rethinking strategies for anaesthesia for ocular injuries $^{[12]}$. Ana Wilson also has discusses and reported alternates to general anaesthesia for ocular injuries ${ }^{[15]}$. Sinha et al report- 
ed various techniques for regional anaesthesia for ocular injuries $^{[16]}$. Shireen Ahmed reported in a current study various levels of sedation as well as sedation along with topical anaesthesia for wound repair in open globe injury ${ }^{[17]}$. Ghai found subtenon block a better alternative with regards to post-operative analgesia as compared to fentanyl for cataract surgery in children ${ }^{[18]}$. Joselito et al reported regional and general anaesthesia in cataract surgery $^{[19]}$. Hakim et al reported augmented topical anaesthesia used for strabismus surgery in adults ${ }^{[20]}$. Besset et al reported intravenous propofol for emergency procedures in children ${ }^{[21]}$. Goldberg reported post-operative nausea -vomiting, over and under sedation, general anaesthesia complications, gastric contents aspiration, cardiac complications, allergic complications, hepatic and renal complications. PONV was documented in 5\% cases only ${ }^{[22]}$. Robb reported general anaesthesia with intubation is safe technique for irrigation in lacrimal passage ${ }^{[9]}$. We are not aware of and have not come across any database published with such a large series.

\section{Conclusion}

It is an inescapable conclusion that surgery specific anaesthesia is very effective method. Endo tracheal intubation is safe and effective strategy for lacrimal surgeries. Regional anaesthesia with sedation or general anaesthesia is effective for cataract, retinal or strabismus surgeries in children.

Conflict of interest: Authors do not have any financial interest in any aspect of this study.

\section{References}

1. Gilbert, C., Foster, A. Childhood blindness in the context of VISION 2020 Right to sight. (2001) Bull World Health Organ 79(3): 227-232.

2. Dandona, L., Gilbert, C. E., Rahi, J. S., et al. Planning to reduce childhood blindness in India. (1998) Indian J Ophthalmol 46(2): 117-122. 3. Long, V., Chen, S., Hatt, S. Surgical interventions for bilateral congenital cataract. (2006) Cochrane Database Syst Rev (3): CD003171.

4. de Carvalho, K.M., Minguini, N., Moreira Filho, D.C., et al. Characteristics of a pediatric low-vision population. (1998) J Pediatr Ophthalmol Strabismus 35(3): 162-165.
5. Msukwa, G., Njuguna, M., Tumwesigye, C., et al. Cataract in children attending schools for the blind and resource centers in eastern Africa. (2009) Ophthalmology 116(5): 1009-1012.

6. Shah, M.A., Shah, M.S., Applewar,A., et al. Ocular Trauma Score as a predictor of final visual outcomes in traumatic cataract cases in pediatric patients. (2012) J Cataract Refract Surg 38(6): 959-965.

7. Vasavada, A.R., Vasavada, S.A., Bobrova, N., et al. Outcomes of pediatric cataract surgery in anterior persistent fetal vasculature. (2012) J Cataract Refract Surg 38(5): 849-857.

8. Robb, R.M., Petersen, R.A. Outcome of treatment for bilateral congenital cataracts. (1992) Trans Am Ophthalmol Soc 90: 183-194.

9. Robb, R.M. Congenital nasolacrimal duct obstruction. (2001) Ophthalmol Clin North Am 14: 293 - 307

10. Stead, S. W. General anaesthesia for ophthalmic surgery. (1998) Ophthalmol Clin North Am 11: 25-37

11. Corcino, A. J. Anesthetic considerations for pediatric ophthalmologic surgery. (1995) Todays OR Nurse 17(4): 16-21.

12. Gayer, S. Rethinking anaesthesia strategies for patients with traumatic eye injuries: Alternatives to general anaesthesia. (2006) Current Anaesthesia \& Critical Care 17(3-4): 191-196.

13. Auffarth, G.U., Vargas, L.G., Klett ,J., et al. Repair of a ruptured globe using topical anaesthesia. J Cataract Refract Surg 30(3): 726-729. 14. Boscia, F., La Tegola, M.G., Columbo, G., et al. Combined Topical Anaesthesia and Sedation for Open-Globe Injuries in Selected Patients. (2003) Ophthalmology 110(8): 1555-1559.

15. Anna Wilson. Anaesthesia for emergency eye surgery updates in anaesthesia 46-50

16. Sinha, A. C., Baumann, B. Anaesthesia for ocular trauma. (2010) Curr Anaesth Critical Care 21(4): 184-188.

17. Ahmad, S. Sedation Techniques in Ophthalmic Anaesthesia. (2006) Ophthalmol Clin North Am 19(2): 193 - 202.

18. Ghai, B., Ram, J., Makkar, J.K., et al. Subtenon block compared to intravenous fentanyl for perioperative analgesia in pediatric cataract surgery. (2009) Anesth Analg 108(4): 1132-1138.

19. Navaleza, J.S., Pendse, S.J., Blecher, M.H. Choosing Anaesthesia for Cataract Surgery. (2006) Ophthalmol Clin N Am 19(2): 233 - 237.

20. Hakim, O. M., El-Hagl, Y.G., Haikal, M.A. Strabismus surgery under augmented topical anesthesia. (2005) J Aapos 9(3): 279-284.

21. Bassett, K. E., Anderson, J.L., Pribble, C. G. Propofol for procedural sedation in children in the emergency department. (2003) Ann Emerg Med 42(6): 773-782.

22. Goldberg, M. Complications of Anaesthesia for Ocular Surgery. (2006) Ophthalmol Clin North Am 19: 293 - 307
Ommega Online Publishers

Journal Title: Journal of Anesthesia and Surgery (JAS)

Journal Short Name: J Anesth Surg
Journal ISSN: 2377-1364

E-mail: anestheisa@ommegaonline.com

Website: www.ommegaonline.com 